\title{
The Acquisition Strategy Model to Minimize a Risk in a Global Competition
}

\author{
Judi Achmadi \\ Student of Management Science Doctorate Program \\ School Of Post Graduate Universitas Pendidikan Indonesia \\ PT. Sigma Cipta Caraka (Telkomsigma) \\ Indonesia \\ judiachmadi67@gmail.com
}

\author{
Katharina Priyatiningsih \\ Student of Management Science Doctorate Program \\ School Of Post Graduate Universitas Pendidikan Indonesia \\ Asset Management Study Program \\ Politeknik Negeri Bandung \\ Bandung, Indonesia \\ katrinapry@yahoo.com
}

\begin{abstract}
Advance in the rapidly growing Information technology makes the telecommunication services players need to always adjust the right company's strategy at high speed. It was heavily influenced by the customers of information technology in various countries in meeting their information needs. This study aims to determine the extent of the corporate strategy to enter the international market based on consumers to win the global competition. The orientation of the company in the company's strategy to lead the international market and win the global competition. Indonesian telecommunications Services Company, as a research unit, has a horizontal growth with the expansion of the products to the international market. The market growth of four from ten countries are the company's corporate strategy achievement which been built with a focus on telecommunications customer service. Using descriptive method involving company managers as survey respondents, we are getting real results from the company's strategy to enter the international market and win in the global competition through acquisitions and marketing strategies. This acquisition is targeted on neighboring countries that have close similarity with Indonesian culture, or countries with strong cultural ties, while the marketing strategy focuses on the development of new capabilities and services to existing customers. The second variable of the strategy of customer-driven company, namely the acquisition and marketing strategies could further strengthen the implementation of the five core concepts in international business, liabilities from abroad, the company the advantage of being specific, country-specific advantages (CSAs), global integration and local responsiveness.
\end{abstract}

Keywords - corporate strategy, acquisition, marketing strategy, global competition

\section{INTRODUCTION}

Countries, industries and companies enter the international market through the export and import activity, by reason of international trade has a comparative advantage either naturally or deliberate national policy that provides unique benefits in global competition. Porter argues that the advantage of certain industries in different countries depending on the four aspects of the factor conditions, demand conditions, corporate strategies, competition structure and related industries (Zámborský, 2016).
Globalization has triggered changes in political, social, cultural, technological and economic significant in market conditions. In particular, since the mid-1990s the world economy has undergone radical changes in technology, especially in information and communications technologies. This changes in technology and the opening of global markets has led to increase the competitive pressure on the monopoly of telecommunication operator (Scalera, 2012). Advance in the rapidly growing information technology makes telecommunication services company players who play in the global market will always have to adjust right the company's strategy at a high speed. This condition is strongly influenced by customers of information technology in various countries in meeting the required information consumption

Oberer and Erkollar (2015) in his research about telecommunication market say that for modern organization is important to emphasize the increase in agility and competitiveness, doing business in global market and also involved in the alliance. Telecommunication industry constantly going through changes or upgrade that appropriate in order to increase the value of human life. The development of telecommunication service sector has positive and negative aspect that need to be balanced by with strategic planning (Deogaonkar and Washimkar, 2014),

Strategic planning is a systematic process which is documented to take some key decisions in an organization, seen as whole, and can be developed in the next few years. Strategic planning is often called "Corporate-level strategy" or "Corporate Strategy", or "Corporate Strategic Planning", and the success of these strategy implementation is based on the collaboration and the alignment across the organization as whole, it is useful to distinguish between levels of strategy.

Knowing the importance of strategic planning or corporate strategy to enter the international and global market, this paper aim to determinate the extent of the corporate strategy to enter international market based on customer to win the global competition.

The failure of the acquisition is influenced by variety of factors. Risk aspect such as cultural issues is neglected. On the other hand the attention to culture is weaker than other strategic aspect such as financial or policy. Moreau (1998) stated that management controls were a part of the acquisition process that 
was not explicitly discussed in the standards or literature. Ellis and Noy (2003) said that risk: a neglected component of strategy formulation. Mark (2011) said that managing culture, however, is Often a low priority when executives are consumed with the deal's financial and strategic aspects. Risk and culture are related but there is little attention in acquisition strategy as instrument to minimize risk including in IT company.

Research on acquisition strategy in the IT industry based on cultural considerations are still rare. Culture as a tool to reduce the risk in acquisition, as a control for IT enterprise (acquisition culture- models). Culture used as a tool to provide satisfactory services to customers. Culture model provides a framework of control strategies in acquisition. Culture provide operational framework to understand customers. Culture as an unidentified variables that affect the success of the acquisition and has not been widely explored.

\section{LITERATURE REVIEW}

\section{A. Corporate Strategy:}

Level of strategy according C.Priangle \& M.Ktoll (1998) consists of corporate strategy, business strategy and functional strategy. Corporate strategy defines in what business or industry the company will run, business strategy or strategic business unit (SBU) define how the company will compete in the selected business or industry and achieve sustainable competitive advantage, the functional strategy define every SBU has had functional area of finance, marketing, operation and human resource (Wheelen and Hunger,2012). Xue and guo (2013) define corporate strategy is composed of strategy formulation and strategy implementation

Growth strategy is a strategy that very attractive for two principal reason: first, the growth based on increased market demand so it covers the weakness of a company when the market stable or declining, and second, the company growth offering a bigger chance for self-improvement, promotion and more interesting work, especially for CEOs.

One of the basic of growth strategy is concentration that the concentration in the product line(s) in the existing industry; if the company existing product line have the real growing potential. The concentration of resources on this product line is the most logical growth strategy, with two concentration growth strategy, that is vertical growth and horizontal growth. Horizontal concentration growth is corporate strategy with directional strategy issue, which is a growth oriented strategy as the overall corporate direction with management business under it to determinate what market should be entered into by the company in its industry. The growth can be achieved by expanding the company product to different geographic location and/or increase the range of product and service offered to the existing market.

Growth strategy can be categorized based on internal or external growth. Internal growth is divided into global market and domestic/national market condition. External growth is divided into cooperation in the form of mergers, acquisitions and strategic alliances.

\section{B. Acquisitions:}

Acquisition are a relative quick way to enter the international territory, which is buying other company that already operating in that region. Acquisition resulting a synergy that company with complementary product line to be more powerful with better distribution network.

Lewin and Johnston also highlighted the policy analysis that are important changes in the work contract and it implication to the company ability to compete (Zahra, 2000). Long-term Work contract in horizontal growth as partial ownership of full ownership is to indicate the extent to which a company operates in a number of geographic location on the same "spot" in the industry's value chain to produce horizontal integration. Lin et al (2005) said that Mergers and acquisitions (M\&A) is treated as a long-term strategic orientation based on human resource advantage rather than a tactic to pursue shortterm goals. Agnihotry (2013) said that acquisitions is used extensively by managers as a tool of expansion strategy.

\section{Marketing Strategy :}

Globally the multicultural collaborative in information techniques organization tend to grow faster. The availability of data and software solution as information techniques product considered through cross-cultural issue and cultural dialogue so the model can be used to recognize the general difference between difference cultures (Oberer and Erkollar, 2015).

In term of strategy, Telecommunication Company has the development to get closers with their customer by making an interesting offer that is adding more related services to them. (Stancu and Meghisan, 2014). The other reason for that development also because advance in information technology that raise the customer expectation to have more choice and better service, other operation mechanism must adjust to improve operational efficiency and remain competitive (Chang, Fang and Yen, 2005).

\section{Global Competition :}

Competitive strategy is a combination from the ultimate objective of a company that is trying to achieve and as a means (policies) to achieve its target. Companies have a different term for some concept are described, for example, some company use term like "mission" or "objective" not "goal", and some other company use "tactics" not "operation" or "operational policy" (Porter, 1998).

Given the recent experience of some countries, privatization has the potential of causing self-employed business to grow, though also occur a few obstacles that can slow down the economic transformation and organization process. Victor V. Cordell and Erin A.Berland, say that countries have different policy and goal, have incentive to a collaboration that involve all parties to create a "win-win" situation in global trading. (Zahra, 2000) 


\section{RESEARCH METHOD}

This paper is based on case studies of telecommunications company in Indonesia namely TELKOM. Lee (1989) and Yun (2003) stated that management in telecommunication service is a very complex one and using study case is the simples approach for the researcher to give more comprehensive understanding about it (Kang, 2010).

This research is a descriptive case study. The data collected mainly through primary and secondary source, primary data obtained by information gathering through indepth interviews. Key persons are CEO of Telkom, Executive Board, Director of Compliance \& Risk Management using both purposive and snowball technique. Secondary data are management reports and working paper of TELKOM. Analysis data is spiral, Once data are collected, organized and manage. Constructionist analysis model is used to analyze document, observation and interviews data (Flick, 2014)

\section{CASE STUdy}

Before presenting the case studies result, it's necessary to understand Telekomunikasi Indonesia (TELKOM) company profile as one of Indonesia telecommunication service provider and then explained how the company determines the strategy based on the customer as the strategy to enter the global competition in telecommunication services.

\section{A. Company Profiles}

Telekomunikasi Indonesia (TELKOM) have vision, mission and strategic objective for 2016-2020. TELKOM vision is "To be the digital king in Indonesia", and "Lead Indonesia Digital innovation and globalization" as its mission. Strategic objective in 2016-2020 is to be the market capitalization for telecommunication in Asia-Pacific as described in Figure 1. as:

The detail of TELKOM strategic objective can be described

1) As vision and mission is decided, then strategic objective derived to aspirational objective and business objective. Aspirational objective of TELKOM is to be the top from 10 market capitalization of telecommunication in AsiaPacific until 2020, with two business objective.

2) The first business objective is achievement in enterprise value (EV) at 650 billion IDR in 2020 based on "Base-Base scenario", scenario pessimistic or based line. The second business objective is TELKOM target to become the best 10 operators in Asia-Pacific as in 2016 TELKOM is on 12 position.

3) TELKOM growth is not only from its existing product development (organic) but also from the acquisition of other company (inorganic). This organic and inorganic is evenly divided by three case: conservative, base and stretch. Every case has different organic value start from 450 billion IDR, 500 billion IR and 650 billion IDR, and for the inorganic start from 50 billion IDR, 100 billion IDR and 350 billion IDR. The total of organic and inorganic value based on the same case then can be combined in a matrix with minimal value at 450 billion IDR and maximal value at 1000 billion IDR.

4) Based on the "Base-Base Scenario" or the pessimistic scenario, the total value of at least EV is 650 billion IDR as an alternative to (1), with a value of 550 billion organic and inorganic 100 billion IDR. When the value of organic increase towards the stretch with a value of 650 billion IDR then the value of the inorganic-based line of 100 billion IDR, total EV as an alternative (2) amounted to 750 billion IDR. Conditions were more optimistic occur in organic-based lined with 550 billion IDR and inorganic with stretch case at 350 billion IDR as a third alternative, the total EV of 900 billion IDR. Last Alternative (4) as an optimistic target achievement is to stretch the value of organic and inorganic 650 billion to 350 billion IDR case so that the total EV of 1000 billion IDR.

\section{B. TELKOM Corporate Strategy Results:}

To achieve the strategic objective, TELKOM develop five key insights of international expansion ( $\mathrm{InEx}$ ) in their strategic rationale which consist of Telkom Vision, Global Standard Player, Leveraging Global Opportunity, Managing Risk and a Great Global Player.

Develop InEx strategies with TELKOM vision, "To be dominant player in the region", contribute optimally to Indonesia, TELKOM need to be on top and become the dominant player in the region with global standard player, InEx strategy is expected to compete and develop character to get more confidence, creditability and also calibration.

Leveraging global opportunity in the preparation to develop the strategy is used as a big opportunity in regional and global market when TELKOM have the ability and the required capital. This condition is the right time to grow in the regional and global market when the domestic market growth is start to declining.

Developing InEx strategy with managing risk is needed to risk diversification (forex risk, operational risk and other), but as a great global player, the developed strategy need to pay attention to the unlimited environment so if the strategy cannot be upgraded then the company must adapt with the competition so it doesn't extinct. InEx as TELKOM choice for strategic reasons is very important for long-term survival TELKOM. TELKOM always afford to update it resource using innovative source and hardware through leveraging global opportunities and risk diversification which describe the reality about what happen in today global condition and the implication what happen.

InEx entry strategy use high certainty level that divided into three stage that is preparation, start to enter through the easy paths and close big-deals. There 4 part that need to be prepared that is internally develop a vision, structure and system; prepare G-to-G support especially market target, and other thing related to big-deals; prepare partnership and collaboration, get the right local partner(s); and preparing comfortable competency, knowledge from learning by doing. Furthermore, started to go through an easy way, namely to take the opportunity to exploit comparative advantage and entered through the acquisition or establishment of a new company. 
The last stage of close big-deal is we do not need to care small transaction, but large transaction that need to be secured as it will have a significant impact. Entry strategy on InEx designed by TELKOM is in line with the growth strategy to enter global market with "internal entry" and "external entry", and the choice is effectively used in the acquisition of global competition.

\section{Corporate Strategy-Based on Consumers in A Global Competition}

InEx need some benchmark based on people or telecommunication business through two focus with organic focus as developing business in existing product and inorganic focus as acquisition other company.

Organic growth with focus on corporate customer have a strategy like:

1) Focus on serving global MNCs expanding into the growing Chinese market

2) Expand network and product portfolio to offer seamless E2E ICT services to MNCs

3) Set up a network of international subsidiaries in the key developed business markets where the MNCs entering the Chinese market are based to try to target the HQ MNC accounts

4) Focus on serving UK based global MNCs and expanding outside of the UK to the countries that the MNCs do business in

5) Set up offices in clients' target countries to provide seamless global connectivity \& IT services

6) This resulted in an expansion into high-growth regions like Middle East, Africa and South East Asia

In organic growth strategy with focus at corporate customer there is a comparative potential from TELKOM that we can obtained:

1) Indonesia witnessing an economic "boom" similar to what China experienced

2) Telkom has the opportunity to replicate this strategy with global MNCs expanding to Indonesia

3) As limited global MNCs are based in Indonesia, this strategy is not replicable on a global scale

4) Within South East Asia, Telin could pursue this strategy in support of regional Indonesian companies

Inorganic growth that focus on customer footprint have strategy like:

1) Establish domestic base: The company aggressively builds up local market base

2) Expand core Telco business internationally: Value driven through international acquisitions and new ventures in core Telecom business

3) Become full scale global TIMES player: Focus is to develop new capabilities and provide new services to existing customers

In inorganic growth strategy with focus at customer footprint there is a comparative potential from TELKOM that we can obtained:
1) Telkom missed the first mobile operator acquisition cycle and is now focused on IME industries which create a synergy for the Group business and on taking an opportunistic approach in Telecom

2) Acquisition targets are best close to Indonesia or within countries which have strong cultural ties

Figure 1 show four customer footprint (Indonesia with current: Singapore, Hong Kong, Timor Leste, Australia) become ten customer footprint with additional near in the future: Myanmar, Malaysia, KSA, Macao, Taiwan, USA in 2013. Other possibilities will add more 13 customer footprint with PNG, Brunei, South Korea, North Korea, NZ, Iraq, Kuwait, Bahrain, Jordan, Lebanon, Rep. Sudan, South Sudan and Morocco. The next big challenge is China, India and Japan - First telecommunication then "TIMES". Furthermore, for 1823 footprint (in 2014) can be developed a strategy through MPBN (Money - People - Border - Network) approach.

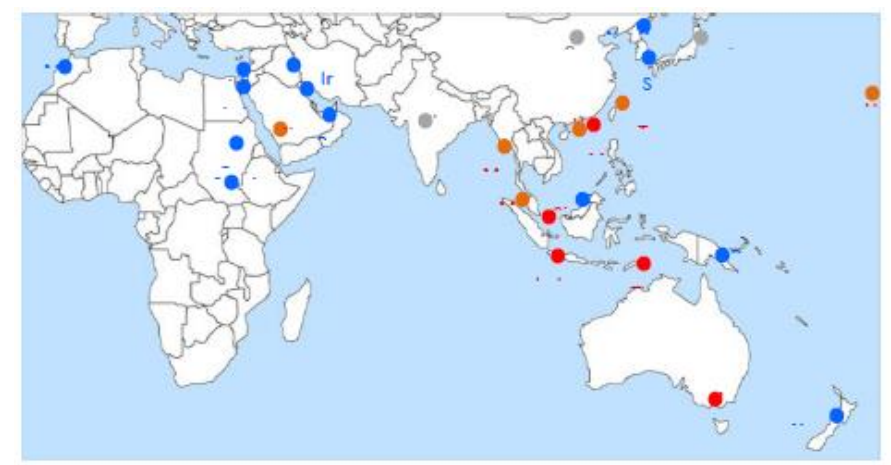

Fig. 1. Strategic Approach MPBN (Money - People- Border - Network) pada aset TELKOM

\section{DISCUSSION AND CONCLUSION}

Close similarity with Indonesian culture is become paradigm in acquisition strategy. To minimize risk. Culture is a strategic aspect that is neglected component of acquisition strategy formulation. For Telkom, Culture provides both a framework for controlling and provide the operational framework to understand customers. Culture as an unidentified variables that affect the success of the acquisition

The result of TELKOM corporate strategy refers to Radomska Joanna (2014) opinion that in the concept of strategic management proposed in the literature, there was a clash between two major trends, where emphasis is on the important principle of adapting to changes in the environment (Prahalad, Hamel, 1990; Collins and Montgomery, 1995), which remain as the opposition. Between organic and inorganic have different focus and strategy, organic emphasis on the importance of competition and resource as factors that decided the (internal) strategy, inorganic more emphasis to adapt with the change in environment (external).

Similarity of Culture will make understanding about customer become deeper. Company will be more understand about customer Values. Culture as a tool to solve its problem of external adaption and internal intergrationin of acquisition 
including customer service problem solution. Understand the other similar culture is a strategic acquisition aspect and operational frame work to serve better.

Karadal, Ḉelik and Saygin (2013) cites Wenstop and Myrmel (2006), said the structure allows the company value system consisting of three categories. The first is the core value that describe the attitude and the nature from integrity, honesty, openness and impartiality of an organization. The second category is value of the task that the organization has chosen laws and regulations voluntarily. The last category consists of consequential value that will impact the organization activity.

\section{ACKNOWLEDGE}

We thank our colleagues from Telkom, Telkomsigma and Universitas Pendidikan Indonesia who provided insight and expertise that greatly assisted the research, although they may not agree with all of the interpretations/conclusions of this paper.

\section{REFERENCES}

[1] Chang Jane, Xiang Fang, David C. Yen. 2005. China's telecommunication market for international investors: opportunities, challenges, and strategies. Technology in Society 27 (2005) 105-121

[2] Deogaonkar Anant, Gaurav Washimkar. 2014. Impact of Changes In Service Sector in Shaping Business and Society Telecommunication Industry. Procedia Economics and Finance 11. pp 495 - 499
[3] Kang Yoolee, Min-Ho Ryu, Seongcheol Kim. 2010. Exploring sustainability management for telecommunications services: A case study of two Korean companies Journal of World Business 45 pp 415 421

[4] Karadal Himmet, Cemile Çelik, Muhammet Saygin, 2013. Corporate Values on Strategic Planning Process: A Research about the Universities in Turkey. Procedia - Social and Behavioral Sciences 99 ( 2013 ) 762 770

[5] Oberer Birgit, Alptekin Erkollar. 2015. Sustainable Knowledge Management shown In The Example of a Company Operating On The Telecommunications Market. Procedia Economics and Finance 26 ( 2015 ) pp 946 - 952

[6] Porter Michael E. 1998.Techniques for Analyzing Industries and Competitors - New introduction $\odot 1998$ by The Free Press

[7] Radomska Joanna.2014. Linking the main obstacles to the strategy implementation with the company's performance. Procedia - Social and Behavioral Sciences 150 ( 2014 ) 263 - 270

[8] Scalera Francesco. 2012. Development Strategies of Telecommunication Company Liberalisation. A Case Study: Telecom Italia. Procedia Social and Behavioral Sciences 58 ( 2012 ) 149 - 158

[9] Stancu Ion, Georgeta-Madalina Meghisan. 2014. Strategic planning based on consumers' decision making process towards mobile telecommunications operators. Procedia Economics and Finance 15 ( 2014 ) $1528-1534$

[10] Wheelen Thomas L and J David Hunger.2012. Strategic management and business policy : toward global sustainability - 13th ed. Pearson Education, Inc., publishing as Prentice Hall

[11] Zahra . Shaker A. Global Competitiveness And Corporate Strategy In The 21st Century. 2000. CR Vol. 10(1)

[12] Zámborský Peter. 2016. International Business And Global Strategy. 1st Edition @ P Peter Zámborský \& bookboon.com 